\title{
EFFECTS OF VARIOUS FACTORS ON THE VIV-INDUCED FATIGUE DAMAGE IN THE CABLE OF SUBMERGED FLOATING TUNNEL
}

\author{
Gang Luo ${ }^{\text {a }}$ \\ Jianxun Chen ${ }^{\text {a }}$ \\ Xiaojun Zhou ${ }^{\text {b }}$ \\ a) Chang'an University,China \\ b) Southwest Jiaotong University, China
}

\begin{abstract}
According to the modal superposition method, the vortex vibration procedure of submerged floating tunnel cable was compiled using Matlab, based on the calculated results, the fatigue damage was predicted. The effects of various factors, such as cable density, cable length, and pretension and velocity distribution on vortex induced fatigue damage in the cable were studied. The results show that velocity distribution has more effect on the cable fatigue damage than cable length, cable density and pre-tension. Secondly, cable length has also relatively effect on the cable damage fatigue, cable density and pretension has limited in a certain range.
\end{abstract}

Keywords: submerged floating tunnel cable; vortex induced vibration; fatigue damage; factor analysis

\section{INTRODUCTION}

Submerged floating tunnel suspends in the certain depth underwater by the balance between gravity, buoyancy and the support system, and maintains the stability of the suspension by the tunnel support system [8]. When the buoyancy floating tunnel suffers is greater than its gravity, the anchor cable will be used to connect it with underwater foundation to balance the remaining buoyancy. As a support structure of the floating tunnel, the stability of anchor cable in the environment of the waves and the flow directly affects the stability of the floating tunnel, while the anchor cable will generate alternating dynamic stress in the vortex-induced vibration, and fatigue damage will occur in the long-term effect, potentially causing fracture damage, even the entire tunnel devastating disaster. Therefore, to the structural design, safety and durability evaluation of submerged floating tunnel, it has important theoretical significance and practical value to deeply study the fatigue damage and structure broken of the anchor cable of floating tunnel under the vortex-induced vibration, as well as the analysis about the durability of floating tunnel anchor cable.

The vortex-induced fatigue damage of flexible structure is one of the main factors of structural failure, so the main purpose of the experimental and theoretical study of vortexinduced vibration is to predict structure vortex-induced fatigue damage. The flexible structure vortex-induced damage prediction are different because of the different methods of vortex-induced vibration analysis.Vikestad [13] proposed a simplified method to forecast riser vortex induced fatigue damage under uniform flow in his doctoral thesis, in which ,stress range was substituted by the riser vortex-induced response the biggest displacement. While it does not consider the long-term structure of the vortex-induced vibration of alternating stress distribution, which will lead to forecasting structure too large. Meling et al [7] used the orthogonal empirical function method to simplify the measured flow rate dates, and then get the velocity distribution of riser 
design, thus predict the riser vortex-induced vibration. Trim et al [9] reduced the vortex induced vibration fatigue damage through the installation of suppression devices in experimental research. J.K Vandiver [11] developed an experience coefficient modal analysis method based on the forced vibration test to calculate riser vortex induced vibration fatigue damage under different velocity distribution .J R Chaplin [2] compared Riser vortex-induced vibration test data with different numerical computation structure, and drew some meaningful conclusions.

This paper compiles the program to forecast the Vortex-induced vibration fatigue damage of floating tunnel based on the theory of vortex-induced vibration and modal superposition method. First, it introduces the related knowledge of vortex-induced vibration and modal superposition method, and then verifies the algorithm of this chapter by JR Chaplin experiments.

\section{VORTEX-INDUCED VIBRATION AND MODAL SUPERPOSITION METHOD}

\section{VORTEX-INDUCED VIBRATION EQUATION}

Fig. 1 shows the structure model of floating tunnel supported by the anchor cables in the water and simplified form of anchor. The anchor cable usually consists of wire or strand, which can be simplified for a simply supported beam, so we can make the assumptions as follow, e.g. in the early work [6].

1) It is assumed that the anchor cable tension does not change along the anchor cable length, because the anchor cable pre-tension is much larger than the gravity of the structure

2) The anchor cable's geometry, sectional form, and the mass distribution does not change along the Anchor length

3) The flows is Constant shear flow which consistent with $\mathrm{Z}$-axis positive direction in Fig. 1; the vibration of anchor cable is only considered in the plane XOY

4) When the anchor has a certain angle with the flow direction, then flow can be decomposed along the perpendicular to the anchor and the direction parallel to the anchor cable, and only the impact of perpendicular to the anchor cable velocity to structure will be considered.

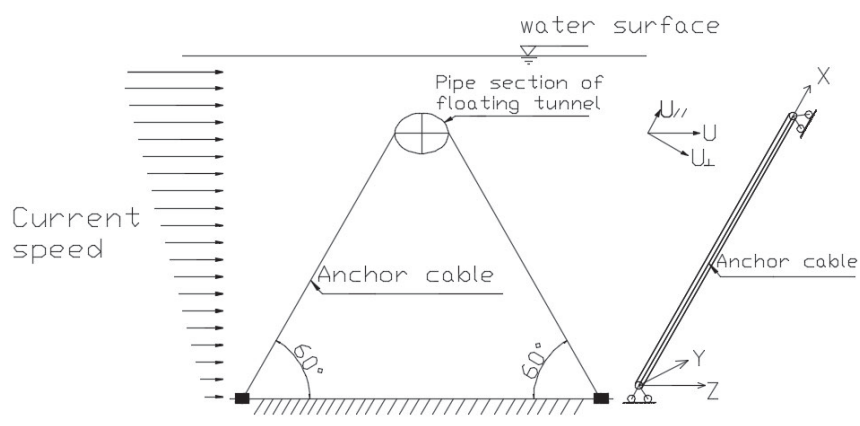

Fig.1. SFT model and cable simple form
Considering the large pre-tension suffered by the anchor cable, the anchor can be simplified as a hinged linear beam, and its vibration equation is:

$E I \frac{\partial^{4} Y(X, t)}{\partial X^{4}}-\frac{\partial}{\partial X}\left[(T-m g X) \frac{\partial Y(X, t)}{\partial X}\right]+m \frac{\partial^{2} Y(X, t)}{\partial t^{2}}+R(X) \frac{\partial Y(X, t)}{\partial t}=P(X, t)$

$E$ - the elastic modulus of anchor cable, $I$ - cross sectional moment of inertia,

$Y(X, t)$ - Lateral displacement, $T$ - pre-tension of anchor cable, $m$ - the mass per unit length of anchor cable, $R(X)$ - System damping,

$P(X, t)$ - Excitation force per unit length.

In order to simplify the analysis process, the formula (1) is nondimensionalized in the longitudinal direction .we make $\mathrm{x}=\mathrm{X} / \mathrm{L}$, and assume $Y(x, t)=\sum_{r} Y_{r}(x) \phi_{r}(t)$, where $Y_{r}(x)=\sin (r \pi x / L) \phi_{r}(t)=A_{r} \sin \left(\omega_{r} t\right)$

Equation (1) can be simplified as follow,

$$
\begin{aligned}
& E I \frac{\partial^{4} \phi_{r}(x, t)}{\partial x^{4}}-\frac{\partial}{\partial x}\left[\left(\frac{T}{L^{2}}-\frac{m g}{L}\right) \frac{\partial \phi_{r}(x, t)}{\partial x}\right]+ \\
& +m \frac{\partial^{2} \phi_{r}(x, t)}{\partial t^{2}}+R_{r}(x) \frac{\partial \phi_{r}(x, t)}{\partial t}=p_{r}(x, t)
\end{aligned}
$$

\section{MODAL SUPERPOSITION METHOD}

The vibration equation of linear damping elastic continuum simply supported beam system can be simplified as,

$$
M_{r} \ddot{\varphi}_{r}(t)+R_{r} \dot{\varphi}_{r}(t)+K_{r} \varphi_{r}(t)=p_{r}(t)
$$

Where $M_{r}, R_{r}, K_{r}$ and $p_{r}(t)$ are modal mass, modal damping, modal stiffness and modal excitation force, which are calculated as follow

$$
\begin{array}{cc}
M_{r}=\int_{0}^{L} Y_{r}^{2}(X) m d X & R_{r}=\int_{0}^{L} Y_{r}{ }^{2}(X) R(X) d X \\
K_{r}=-\int_{0}^{L} T Y_{r}^{\prime \prime}(X) Y_{r}(X) d X & p_{r}(t)=\int_{0}^{L} Y_{r}(X) P(X, t) d X
\end{array}
$$

To r-order modal force, it is considered that the lift only works to structure in the incentive area and lift phase is non-inverting with structure modal speed. So $p_{r}(t)=\int_{L^{r}}\left|Y_{r}(X)\right| P(X, t) d X$ . Based on the centrifugal force model by Blevins [1], 


$$
P(X, t)=0.5 r_{w} D U^{2}(X) C_{L}\left(X, w_{r}\right) \sin \left(w_{r} t\right)
$$

$C_{L}\left(X, \omega_{r}\right)$ is r-order modal corresponding lift coefficient of anchor cable at the $\mathrm{X}$ position ; making r-order Modal velocity as $\dot{\phi}_{r}(t)=A_{r} \omega_{r} \cos \left(\omega_{r} t\right)$,r-order modal excitation power can be expressed as the product of excitation force and modal velocity. $r$-order modal power dissipation power can be expressed as the product of the damping force and modal speed. when the system is in the steady-state response, the excitation power equals dissipation power. Excitation power $\Pi_{i n}^{r}$ and dissipation power $\Pi_{\text {out }}^{r}$ can be express as follows

$$
\begin{gathered}
\Pi_{\text {in }}^{r}=\int_{L^{r}} \frac{1}{2} \rho_{w} D U^{2}(X) C_{L}\left(X, \omega_{r}\right) A_{r} \sin \left(\omega_{r} t\right) \cos \left(\omega_{r} t\right)\left|Y_{r}(X)\right| d X \\
\Pi_{\text {out }}^{r}=\int_{L} R(X) Y_{r}^{2}(X) A_{r}^{2} \cos ^{2}\left(\omega_{r} t\right) d X
\end{gathered}
$$

For periodic excitation force, the power is averaged in the period to simplify the calculation

$$
E_{i n}^{r}=\frac{1}{T} \int_{0}^{T} \Pi_{i n}^{r} d t=\frac{1}{4} \int_{L^{r}} \rho_{w} D U^{2}(X) C_{L}\left(X, \omega_{r}\right) A_{r} \omega_{r}\left|Y_{r}(X)\right| d X
$$

$$
\mathrm{E}_{\text {out }}^{r}=\frac{1}{T} \int_{0}^{T} \Pi_{\text {out }}^{r} d t=\frac{1}{2} \int_{L} R(X) Y_{r}^{2}(X) A_{r}^{2} \omega_{r}^{2} d X
$$

$$
\text { By } \mathrm{E}_{i n}^{r}=\mathrm{E}_{\text {out }}^{r}
$$

$$
\frac{A_{r}}{D}=\frac{\frac{1}{2} \int_{L^{r}} \rho_{w} U^{2}(X) C_{L}\left(X, \omega_{r}\right)\left|Y_{r}(X)\right| d X}{\int_{L-L^{r}} R_{h}(X) Y_{r}^{2}(X) \omega_{r} d X+\int_{0}^{L} R_{s}(X) Y_{r}^{2}(X) \omega_{r} d X}
$$

Where $C_{L}\left(X, \omega_{r}\right)$ is the function of dimensionless displacement. Different $A_{r} / D$ are got by calculated based on different lift model, which need iterative solution. Based on Blevins model [4], $C_{L}(z)=a+b\left(\frac{A_{r}}{D}\right)+c\left(\frac{A_{r}}{D}\right)^{2}, a=0.35$, $b=0.6, c=-0.93$.

The damping model uses the model proposed by Vengugopal Madan [12] in 1996.The damping constant $R_{h}(X)$ denotes unit force per unit velocity and unit length, which is different in the low reduced speed area and the high reduced speed area.

- $\quad$ the low reduced speed area

$$
R_{h}(X)=\frac{\omega \pi \rho_{w} D^{2}}{2}\left[\frac{2 \sqrt{2}}{\sqrt{\operatorname{Re}_{w}}}+C_{K 1}\left(\frac{A}{D}\right)^{2}\right]+C_{K 2} \rho_{w} D U(X)
$$

- $\quad$ the high reduced speed area

$$
R_{h}(X)=C_{K 3} \rho_{w} U^{2}(X) / \omega
$$

Where Empirical parameters $\mathrm{C}_{K 1}, \mathrm{C}_{K 2}$ and $\mathrm{C}_{K 3}$ are Respectively be got as , 0.25, 0.18 and $0.2 \cdot \mathrm{Re}_{w}=\omega D^{2} / v$ $\omega$ is Natural frequency, $v$ is the Kinematic viscosity of the fluid. As for the other symbols, ditto.

\section{FATIGUE DAMAGE ANALYSIS}

There are two types of prediction of fatigue life of marine structures, one is based on fatigue cumulative damage theory and the other is based on the theory of fatigue crack growth. In this paper, fatigue cumulative damage analysis method is adopted which based on the S-N curve and Miner guidelines, the method is simple and the results are reliable. It is assumed that the anchor rope vortex-excited alternating stress meets the random process that the mean is zero in the narrowband smooth, and its peak satisfies the Rayleigh distribution. In the modal analysis process, it is assumed that when the r-order modal drives, the number of Stress amplitude which anchor cable corresponding to in $\mathrm{T}$ is $N_{L}=f_{r} T, \mathrm{~T}=365 \times 24 \times 3600 \mathrm{~s}$. According to the total damage in a year by the Multi-modal vortex-induced vibration in Modal superposition method, $D$ can be expressed as [5]

$$
D=\sum_{r} D_{r}=\sum_{r} \frac{f_{r} T}{C}\left(2 \sqrt{2} \sigma_{r m \mathrm{~s}}\right)^{b} \Gamma\left(\frac{b}{2}+1\right)
$$

$\sigma_{\text {rms }}$ is the alternating stresses rms stress.

\section{ALGORITHM VERIFICATION}

\begin{tabular}{|c|c|c|c|c|c|c|}
\hline $\begin{array}{l}\hat{\overline{0}} \\
\overline{0} \\
\stackrel{0}{0}\end{array}$ & 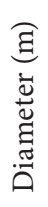 & 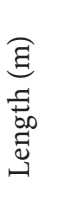 & 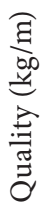 & 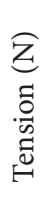 & 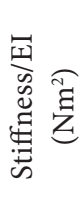 & 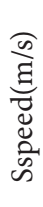 \\
\hline రి & $\begin{array}{l}\stackrel{\infty}{\circlearrowleft} \\
\stackrel{0}{0} \\
\stackrel{0}{0}\end{array}$ & 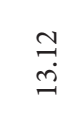 & $\stackrel{\infty}{\infty}$ & 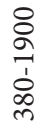 & 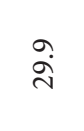 & $\begin{array}{l}0 \\
\stackrel{1}{1} \\
\stackrel{0}{0}\end{array}$ \\
\hline
\end{tabular}

\section{TEST PROFILE}

Chaplin [2] designed a sophisticated test program, which is conducted in the towing tank of the Delft Hydraulics Laboratory of the University of Southampton in the United Kingdom. The length of the pool is $230 \mathrm{~m}$, width is $5 \mathrm{~m}$, and depth is $6.5 \mathrm{~m}$, the upper end of the riser is fixed to the mounting platform locomotives. The test apparatus shows in Fig. 2, riser parameters shows in Tab. 1.

Tab.1. Test riser parameters 


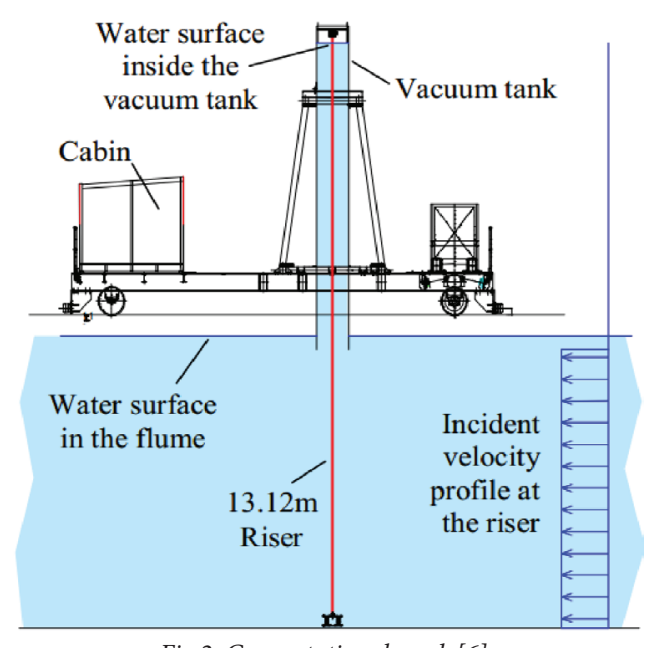

Fig.2. Computational mode[6]

In order to simulate the riser multi-modal vortex-induced vibration under the ladder flow effect in the Test design process, the part of the riser above the pool water surface is placed in the vacuum pipe container which is dragged with the riser model and full of water. So we can simulate the flow of role. The length of the part riser above the pool water surface is $7.22 \mathrm{~m}$, and the flow rate of the water is $0 \mathrm{~m} / \mathrm{s}$, and the speed of flow in the pond is uniform .Both sides of riser are hinged, initial pre-tension is applied on the top, the tension adjustment range is $380 \mathrm{~N}-1900 \mathrm{~N}$.

\section{RESULT ANALYSIS}

Selecting two conditions shown in Fig. 3 (a) and (b), it is found that the calculated result is closer to Chaplin test results and Pan Zhiyuan algorithm results, but the result of SHEAR7 calculation results is too large. In two different conditions, the current calculation dimensionless amplitude and main modes are well agreed with the experimental results, which verify the feasibility of the proposed algorithm in this paper.

\section{THE ANALYSIS OF ANCHOR CABLE VORTEX-INDUCED FATIGUE IMPACT}

In order to figure out the impact on the anchor cable Vortex-excited fatigue damage lead by the related factors ,this section analyzes the impact on the anchor rope vortexexcited fatigue damage by anchor cable density, the anchor cable length, pre-tension and the flow conditions.

According to the actual marine environment, the annual average flow rate conditions of Qiongzhou Strait are selected. The flow rate is linear shear flow along the depth, the flow rate of the upper of anchor is $1.6 \mathrm{~m} / \mathrm{s}$, the flow rate of the bottom of anchor that consolidated with the foundation is $0.2 \mathrm{~m} / \mathrm{s}$. According to the S-N curve parameters of the API-X 'curve fatigue analysis, we adopt $\mathrm{C}=3.74, \mathrm{~b}=2.5 \mathrm{e} 13$.

Tab.2. Cable parameters

\begin{tabular}{|c|c|c|c|c|c|}
\hline 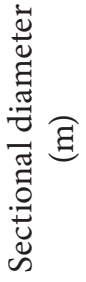 & 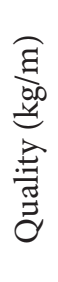 & 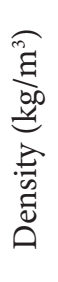 & $\begin{array}{l}\underset{Z}{Z} \\
\stackrel{\Xi}{0} \\
\stackrel{0}{0}\end{array}$ & 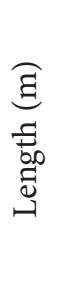 & 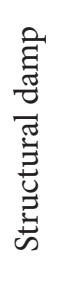 \\
\hline$\stackrel{1}{\sim}$ & $\begin{array}{l}\overrightarrow{1} \cdot \\
\infty \\
m\end{array}$ & $\begin{array}{l}\circ \\
10 \\
\infty \\
\infty\end{array}$ & ஓ & $\stackrel{\bigcirc}{\circ}$ & $\begin{array}{l}\Re \\
\stackrel{\circ}{\circ} \\
\stackrel{0}{0}\end{array}$ \\
\hline
\end{tabular}

\section{IMPACT LEADING BY DENSITY}

This paper adopt three kinds of density, they respectively are $\rho_{1}=1960 \mathrm{~kg} / \mathrm{m}^{3}, \rho_{2}=3925 \mathrm{~kg} / \mathrm{m}^{3}$, and $\rho_{3}=7850 \mathrm{~kg} / \mathrm{m}^{3}$, and the anchor cable is simplified to simply supported beam. Tab. 3 shows the anchor rope modal frequency and immeasurable modal amplitude on the condition of three different qualities.

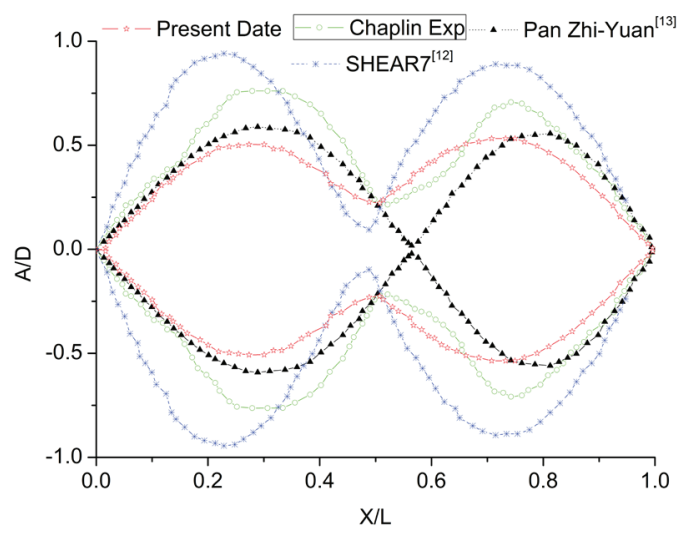

(a) $T=405 \mathrm{~N}, U=0.16 \mathrm{~m} / \mathrm{s}$

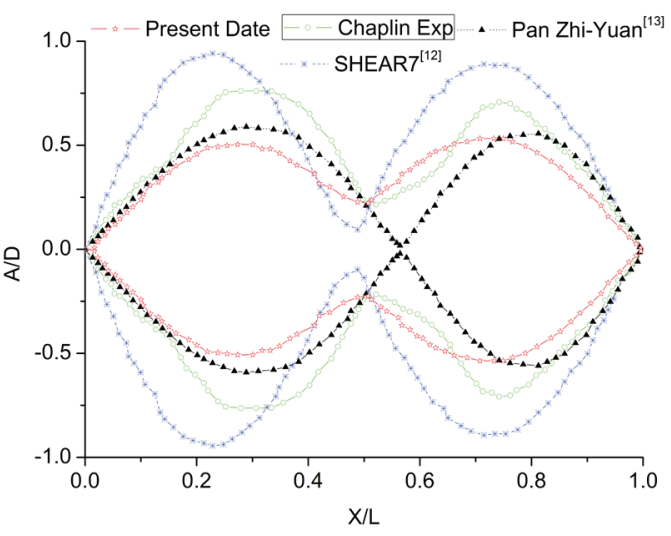

(b) $T=506 \mathrm{~N}, U=0.4 \mathrm{~m} / \mathrm{s}$

Fig.3. Dimensionless amplitude envelope diagram 
Tab.3. Excitation frequency and dimensionless amplitude (modal participation factor)

\begin{tabular}{|c|c|c|c|c|}
\hline $\begin{array}{c}\text { Incentive } \\
\text { mode }\end{array}$ & 2 & 3 & 4 & 5 \\
\hline$\nabla_{1}$ & $0.80 / 0.34$ & $1.14 / 0.31$ & & \\
\hline$\bigotimes_{2}$ & & $0.88 / 0.56$ & & \\
\hline$\square_{3}$ & & $0.65 / 0.2$ & $0.89 / 0.28$ & $1.19 / 0.12$ \\
\hline
\end{tabular}

Note: before "/" is excitation frequency and after is the dimensionless amplitude corresponding to the frequency

From Tab.3, Corresponded to the different densities, the main modes and modal participation coefficients are different. As the density increases, the modes (Dominant modal) order that maximum dimensionless vibration corresponding to increases.

From Fig. 4 the peaks of the stress corresponding to different density are different along the anchor rope longitudinal distribution; the number of peak corresponds to the modal number that contributes mostly to the total stress of the anchor cable. In addition, the maximum amplitude of dimensionless vibration modes number is not necessarily the mode that contributes most stress. For example, when $\rho 1=1960$ $\mathrm{kg} / \mathrm{m} 3$, the second order have the largest non-dimensional vibration amplitude, however, the third mode contributes mostly to the stress, the stress distribution shows three peaks.

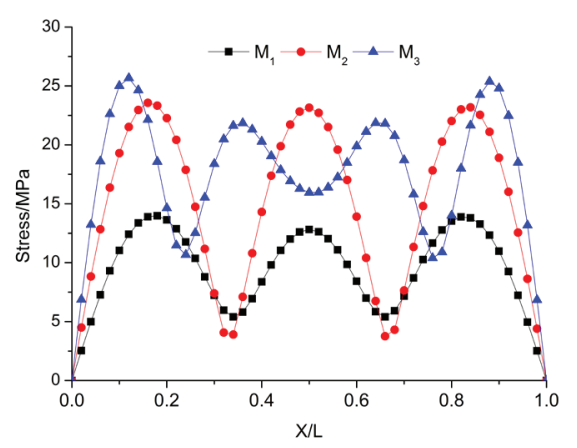

Fig.4. Stress distribution

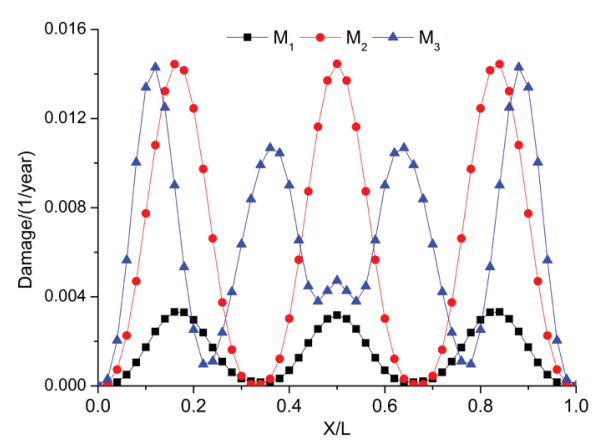

Fig.5. Fatigue damage distribution

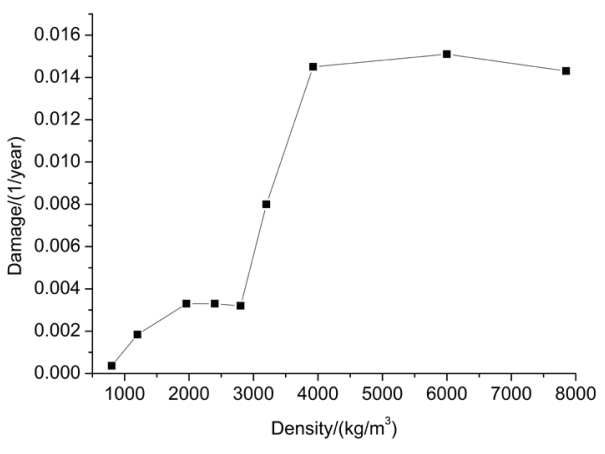

Fig.6. max damage vs density

As is shown in the Fig. 5, the damage is similar with the stress distribution law along the anchor cable vertical distribution, Stress is one of the key factors that affecting the fatigue damage. With the increase of density, fatigue damage is increasing. Thus, in engineering practice, high-strength, low-density material can be adopted so that the fatigue damage of anchor cable can be reduced. Fig. 6 shows the relationship between the anchor cable longitudinal maximum damage and anchor density. As is shown in Fig. 6, the anchor cable damage increases with the density.

\section{IMPACT LEADING BY PRE-TENSION}

Taking the anchor cable length $\mathrm{L}=300 \mathrm{~m}$, other parameters are shown in Tab.2, Comparative anchor cable pre-tension are respectively $F_{1}=800 \mathrm{KN}, F_{2}=1600 \mathrm{KN}, F_{3}=2400 \mathrm{KN}$. Tab. 4 shows the different anchor cable excitation frequency under different tension and the corresponding dimensionless modal amplitude.

Tab.4-1. $F_{1}=800 \mathrm{KN}$ Excitation frequency and dimensionless amplitude

\begin{tabular}{|l|c|c|c|c|c|}
\hline Incentive mode & 10 & 11 & 12 & 13 & 14 \\
\hline Frequency & 0.744 & 0.798 & 0.871 & 0.961 & 1.03 \\
\hline $\mathrm{A}_{\mathrm{r}} / \mathrm{D}$ & 0.1283 & 0.239 & 0.267 & 0.371 & 0.427 \\
\hline
\end{tabular}

Tab.4-2. $F_{2}=1600$ KN Excitation frequency and dimensionless amplitude

\begin{tabular}{|l|c|c|c|c|}
\hline Incentive mode & 9 & 10 & 11 & 12 \\
\hline Frequency & 0.811 & 0.885 & 0.955 & 1.031 \\
\hline $\mathrm{A}_{\mathrm{r}} / \mathrm{D}$ & 0.249 & 0.263 & 0.407 & 0.425 \\
\hline
\end{tabular}

Tab.4-2. $F_{3}=2400 \mathrm{KN}$ Excitation frequency and dimensionless amplitude

\begin{tabular}{|l|c|c|c|c|c|}
\hline Incentive mode & 7 & 8 & 9 & 10 & 11 \\
\hline Frequency & 0.752 & 0.822 & 0.907 & 0.996 & 1.088 \\
\hline $\mathrm{A}_{\mathrm{r}} / \mathrm{D}$ & 0.242 & 0.252 & 0.295 & 0.334 & 0.359 \\
\hline
\end{tabular}

From Tab. 4, with the increase of pre-tension of anchor cable, the anchor cable dominant mode number decreases gradually, the dimensionless amplitude of anchor cable 
corresponding to major incentive modal have little difference, the form of Anchor cables vortex-induced vibration is a multimodal vortex-induced resonance.

Fig. 7 and 8 show the longitudinal rms stress under different pre-tension and fatigue damage distribution of anchor.

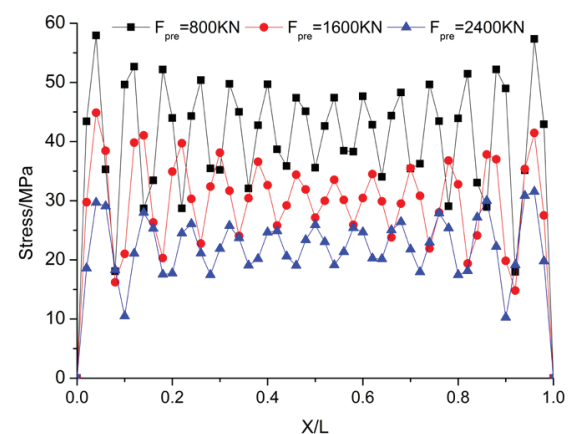

Fig.7 Stress distribution

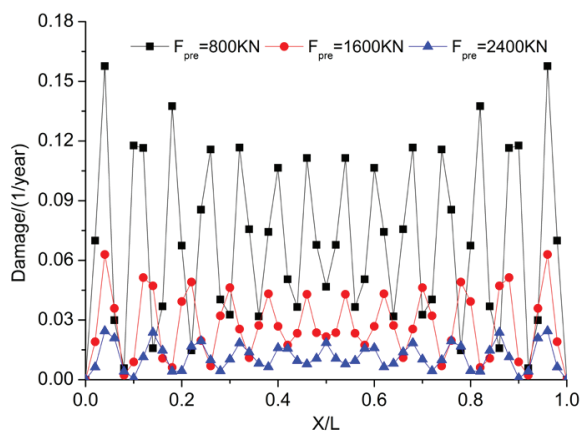

Fig.8 Fatigue damage distribution

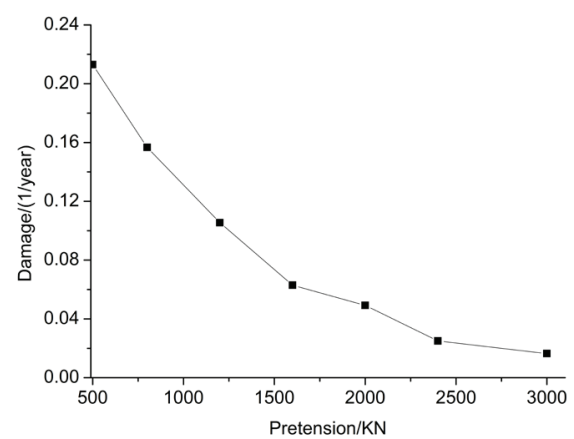

Fig.9. Maximum damage \& pre-tension

From Fig. 7, the anchor cables vortex induced vibration stress decreases with anchor pre-tension increasing. Fig. 8 shows that the distribution of the fatigue damage of anchor in vortex-induced is similar with stress distribution, with the increasing of the pre-tension, the different vertical position fatigue damage of the anchor cable decreases, the maximum damage is also reduces. Fig. 9 shows the relationship between the maximum damage of anchor and pre-tension. Fig. 9 shows that: under the premise that in a small pre-tension, the increasing of the pre-tension leads to the increase of anchor frequency, the increasing of frequency leads decreasing of dimensionless modal amplitude that incentive mode corresponds to, the stress that the anchor cable corresponds to and the maximum fatigue damage also reduced.

\section{THE IMPACT OF ANCHOR CABLE LENGTH}

Selecting the anchor cable parameters and flow parameters showed in Tab. 2, comparing the anchor cable vortex-induced response and the fatigue damage distribution under the condition that the cable length is $100 \mathrm{~m}, 200 \mathrm{~m}$, and $300 \mathrm{~m}$. Tab. 5 shows the excitation frequencies of the different length of anchor cable and the corresponding dimensionless mode.

Tab.5-1. L=100 m Excitation frequency and dimensionless amplitude

\begin{tabular}{|l|c|c|c|}
\hline Incentive mode & 3 & 4 & 5 \\
\hline Frequency & 0.654 & 0.892 & 1.186 \\
\hline $\mathrm{A}_{\mathrm{r}} / \mathrm{D}$ & 0.198 & 0.279 & 0.121 \\
\hline
\end{tabular}

Tab.5-2. L=200 m Excitation frequency and dimensionless amplitude

\begin{tabular}{|l|c|c|c|c|}
\hline Incentive mode & 6 & 7 & 8 & 9 \\
\hline Frequency & 0.676 & 0.776 & 0.866 & 1.011 \\
\hline $\mathrm{A}_{\mathrm{r}} / \mathrm{D}$ & 0.142 & 0.251 & 0.217 & 0.414 \\
\hline
\end{tabular}

Tab.5-3. L=300 $m$ Excitation frequency and dimensionless amplitude

\begin{tabular}{|c|c|c|c|c|c|}
\hline Incentive mode & 10 & 11 & 12 & 13 & 14 \\
\hline Frequency & 0.744 & 0.798 & 0.871 & 0.961 & 1.03 \\
\hline $\mathrm{A}_{\mathrm{r}} / \mathrm{D}$ & 0.128 & 0.239 & 0.267 & 0.371 & 0.427 \\
\hline
\end{tabular}

From Tab. 5, with the increase of length of anchor cable, the anchor cables vortex induced impact excitation mode order increased gradually. Dominant modes also increase. Fig. 10 and 11, respectively, show the anchor longitudinal rms stress and fatigue damage distribution on the condition of different lengths of anchor cable.

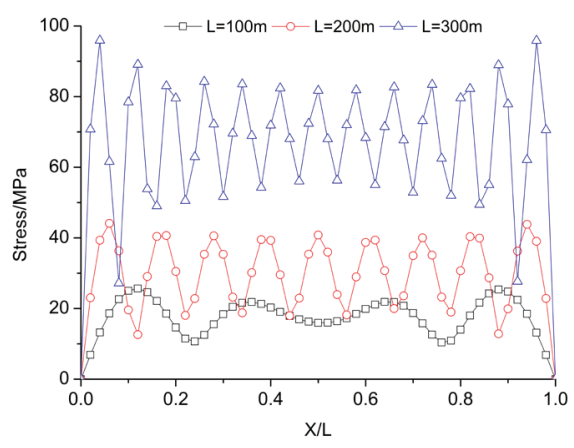

Fig.10 Stress distribution 


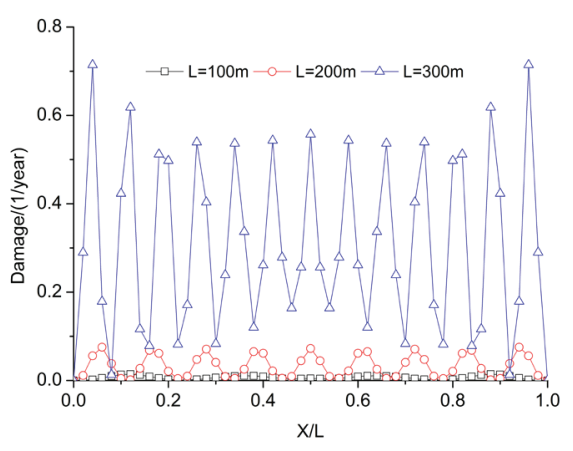

Fig.11. Fatigue damage distribution

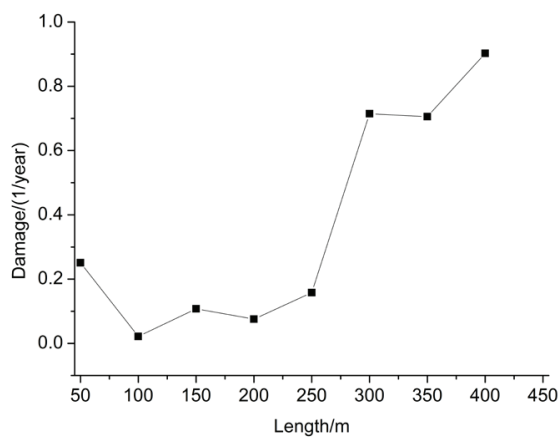

Fig.12. Maximum damage \& the cable length

As is shown from Fig. 10 and Fig. 11, with the increase of the length of anchor, the rms stress and damage of anchor longitudinal different positions increase. Fig. 12 shows the relationship between maximum damage and the length of anchor .From Fig.12, in general, Anchor maximum damage increases with the Anchor length increasing, the local gain is not very obvious.

\section{THE IMPACT OF FLOW RATE DISTRIBUTION}

This section discusses the impact that shear slope affects anchor cable VIV only under the shear flow condition. It is assumed that the length of anchor cable is $200 \mathrm{~m}$; other parameters of anchor are shown in Tab. 2, and it is assumed that the maximum velocity of the upper of the anchor $\mathrm{U}_{\max }=1.6 \mathrm{~m} / \mathrm{s}$, and remains unchanged, Shear rate $\beta=\left(U_{\max }-\right.$ $\left.U_{\text {min }}\right) / L$, respectively are $\beta_{1}=0.007$ (see Tab. 5-2), $\beta_{2}=0.004$, and $\beta_{3}=0.001$, the analysis of Anchor vortex-induced response and fatigue damage. Tab. 6 shows the vortex-induced excitation frequencies under different shear rates and dimensionless modal amplitude.

Tab.6-1. $\beta_{1}=0.004$ Excitation frequency and dimensionless amplitude

\begin{tabular}{|l|c|c|c|c|}
\hline Incentive mode & 4 & 8 & 9 & 10 \\
\hline Frequency & 0.796 & 0.843 & 0.943 & 1.034 \\
\hline $\mathrm{A}_{\mathrm{r}} / \mathrm{D}$ & 0.308 & 0.335 & 0.454 & 0.456 \\
\hline
\end{tabular}

Tab.6-2. $\beta_{1}=0.001$ Excitation frequency and dimensionless amplitude

\begin{tabular}{|c|c|c|c|c|c|c|}
\hline 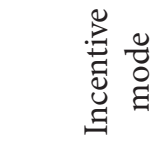 & in & 6 & $a$ & 으 & 二 & $\sim$ \\
\hline Frequency & ભે & r & \begin{tabular}{l}
0 \\
\multirow{2}{*}{} \\
0
\end{tabular} & ¿ُ & $\underset{\sim}{\stackrel{H}{\sim}}$ & $\begin{array}{l}m \\
\infty \\
\text { ma } \\
-1\end{array}$ \\
\hline$A_{r} / D$ & $\begin{array}{l}\hat{\sigma} \\
\text { o }\end{array}$ & $\begin{array}{l}\infty \\
\infty \\
\stackrel{\infty}{0}\end{array}$ & 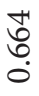 & $\begin{array}{l}\stackrel{+}{0} \\
\stackrel{0}{0}\end{array}$ & $\hat{n}$ & $\stackrel{\hat{\sigma}}{\circ}$ \\
\hline
\end{tabular}

As is shown from Tab. 6, the vortex-induced vibration mode order of anchor cable increases with the decrease of shear rate. Fig. 13 and Fig. 14 give anchor longitudinal rms stress and fatigue damage distribution on the condition of different shear flow rate respectively.

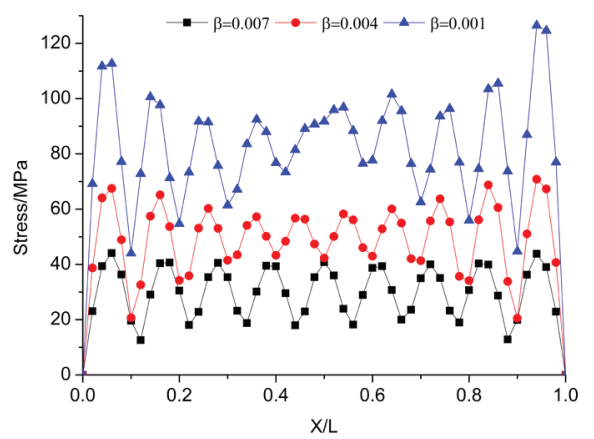

Fig.13. Stress distribution

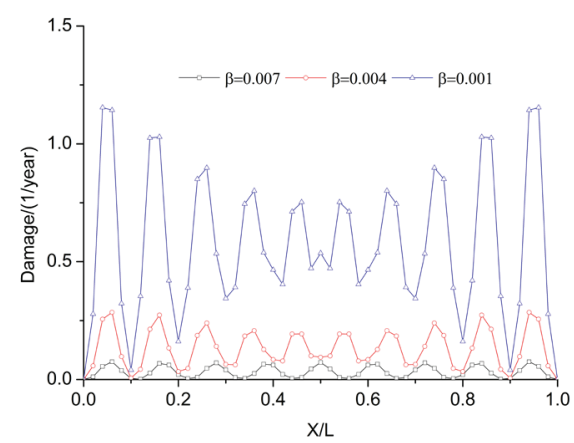

Fig.14. Fatigue damage distribution

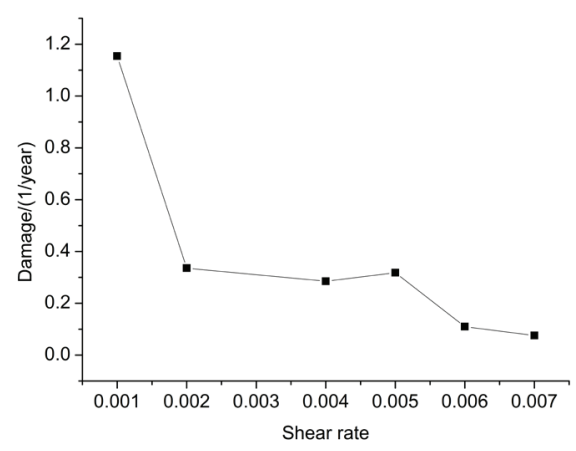

Fig.15. Maximum damage \& the velocity shear rate 
As is shown from Fig. 11 and Fig. 12, the longitudinal rms stress distribution and the distribution of the fatigue damage of Anchor decreases with the increase of shear rate relatively, with large amplitude from this, it is can be found that the fatigue damage of anchors in vortex-induced is large in uniform flow, is relatively small in shear flow. As is shown from Fig. 15, as the shear rate decreases, the anchor maximum damage is significantly reduced.

\section{CONCLUSIONS}

1) With the increase of density of the anchor cable, floating tunnel longitudinal rms stress and fatigue damage reduces, but the damage area changes relatively less.

2) The length of cable affects the anchor cable vortexinduced vibration fatigue damage obviously, as the length increases, the Anchor Cable vortex induced fatigue damage increases, and the range of increasing is large.

3) The impact on the cable fatigue damage from pre-tension is limited, and it is favorable for decreasing the anchor cables vortex induced fatigue damage to increase appropriately the pre-tension; But it should be noted that, with the increasing of the pre-tension, the stress and damage of Anchor also increases correspondingly.

4) The impact on the anchor rope vortex induced fatigue damage from the shear rate of shear flow is very obvious; a weak change from shear rate change will lead to a obvious changes of the anchor rope fatigue damage. Increasing shear rate can significantly reduce the anchor rope fatigue damage.

\section{REFERENCE}

1. Blevins, R.D., Flow-induced vibration, Van Nostrand Reinhold, New York, USA, 1990.

2. Chaplin, J.R., Bearman, P.W., Huera, H.F.J., and Pattenden, R.J., Laboratory measurements of vortex-induced vibrations of a vertical tension riser in stepped current, Journal of Fluids and Structures, Vol. 21, pp.3-24, 2005.

3. Dong, M.S., Ge, F., Hui, L. et al., Research progress in submerged floating tunnels (in chinese), China Journal of Highway and Transport. Vol. 20, no. 4, pp. 101-107, 2007.

4. Gopalkrishnan, R., Vortex induced forces on oscillating bluff cylinders, MIT: Cambridge, MA, USA, 1993.

5. Hu, Y.R., Li, D.Q., and Chen, B.Z., ship and ocean engineering structure fatigue reliability analysis. Beijing, Beihang University Press, 2010.

6. Mai, J.T., Luo, Z.X., and Guan, B.S., Vortex-induced dynamic response of tension legd for submerged floating tunnel under current effect, JOURNAL OF SOUTHWEST JIAOTONG UNINERSITY, 2004, Vol. 39, no. 5, pp. 600-604.
7. Meling, T.S., Eik, K.J., and Nygaard, E., An assessment of EOF current scatter diagrams with respect to riser VIV fatigue damage, Proceedings of the 21th OMAE, Paper No. OMAE2002-28062, Oslo, Norway, 2002.

8. Pan, Z.Y., Cui, W.C., and Liu, Y.Z., The prediction of vortexinduced vibration (VIV) of a slender tensioned riser in a stepped current, JOURNAL OF SHANGHAI JIANTONG UNIVERSITY, Vol. 40, no. 6, pp. 1064-1068.

9. Trim, A.D., Braaten H., Lie, H., and Tognarelli, M.A., Experimental investigation of vortex-induced vibration of long marine risers, Journal of Fluids and Structures, Vol. 21, no. 4, pp. 335-361, 2005.

10. Vandiver, J.K. and Li, L., SHEAR7 program theory manual. Cambridge, MA, Department of Ocean Engineering, MIT, USA, 1999

11. Vandiver, J.K., Research challenges in the vortex-induced vibration prediction of marine risers, Proceedings of the OTC, Paper No. OTC 8098, Houston, USA, 1998.

12. Vengugopal, Madan, Damping and response prediction of a flexible cylinder in a current, Ph.D.Thesis submitted to Dept. of Ocean Eng. MIT. 1996.

13. Vikestad, K., (1998) Multi-frequency response of a cylinder subjected to vortex shedding and support motions. Ph.D. dissertation, Department of Marine Structures Faculty of Marine Technology, Norwegian University of Science and Technology

\section{CONTACT WITH THE AUTHOR}

\author{
Gang Luo \\ Jianxun Chen \\ School of Highway, \\ Chang'an University,Xi'an \\ Shaanxi 710064 \\ CHINA \\ tel.:+00862982332897, fax: +00862982332897 \\ Xiaojun Zhou \\ School of Civil Engineering \\ Southwest Jiaotong University \\ Chengdu 610031 \\ CHINA
}

